\title{
Toward integrated smart city: a new model for implementation and design challenges
}

\author{
Houbakht Attaran • Nahid Kheibari (iD) Davoud Bahrepour
}

Accepted: 27 November 2021 / Published online: 20 January 2022

(C) The Author(s), under exclusive licence to Springer Nature B.V. 2021

\begin{abstract}
In smart city architecture, information and communication technologies are used to improve living standards and its management by citizens and government. Most researchers have divided this structure into six main components: smart people, the smart government, smart environment, smart transportation, smart economy, and smart life. Due to the connection between smart cities and the challenges resulting from their implementation and especially its integration, there exists no perfect solution for the concept of an integrated smart city so far according to our studies. Some more general concepts such as security, ICT infrastructure, and knowledge are not seen integrative in these structures. Therefore, it seems that new sub-components and general extra-components should be added to the existing models to form an integrated structure in such a way that the executive projects are located in their proper place in this structure and create and guarantee the integration of the smart city. Therefore, the requirements engineering of the smart city can also be explained more precisely. This study presents a model of an integrated graph in such a way that besides
\end{abstract}

H. Attaran

Department of Computer Engineering, Khavaran Institute of Higher Education, Mashhad, Iran

N. Kheibari $(\square) \cdot$ D. Bahrepour

Department of Computer Engineering, Mashhad Branch, Islamic Azad University, Mashhad, Iran

e-mail: nahidkheibary@gmail.com maintaining and improving the model of the smart city and existing models, it will fully cover the integration and requirements engineering and methodologies of the smart city in the future. The present paper offers an upgraded model of a six-component smart city structure as a flexible integrated dynamic graph so that beside maintaining the features of existing smart city models, it ensures its integrity, dynamism, flexibility and performance and prevents the failure of smart operations. Due to its flexibility, adaptability and localization, the proposed model presented in this paper can create an integrated solution and facilitating the life cycle of executive systems and enable governments and communities to predict and prevent sudden events such as natural disasters, pandemics like Covid-19 and the like as well as managing and leading their target community in the best way.

Keywords Smart city - Integrated smart city · Integrated model $\cdot$ Internet of things (IoT) · Flexibility · Covid19 · Requirements engineering

\begin{tabular}{|c|c|}
\hline \multicolumn{2}{|c|}{ Abbreviations } \\
\hline IOT & Internet of things \\
\hline ICT & $\begin{array}{l}\text { Information and communication } \\
\text { technology }\end{array}$ \\
\hline IDC & International Data Corporation \\
\hline IMD & $\begin{array}{l}\text { International Institute for Management } \\
\text { Development }\end{array}$ \\
\hline
\end{tabular}


Smart A smart city is a developed urban area that

city creates sustainable economic development and high quality of life by excelling in multiple key areas; economy, mobility, environment, people, living, and government-Business Dictionary.

IOT The Internet of Things (IoT) is a scenario in which objects, animals or people are provided with unique identifiers and the ability to transfer data over a network without requiring human-to-human or human-to-computer interaction.

ICT Refers to technologies that provide access to information through telecommunications. It is similar to Information Technology (IT), but focuses primarily on communication technologies. This includes the Internet, wireless networks, cell phones, and other communication mediums.

IDC Is the premier global provider of market intelligence, advisory services, and events for the information technology, telecommunications, and consumer technology markets. IDC's analysis and insight helps IT professionals, business executives, and the investment community to make fact-based technology decisions and to achieve their key business objectives.

\section{Introduction}

The process of urbanization is currently taking place at a rapid pace on a global scale. Every year, millions of people migrate from rural to urban areas to gain comfort and economic opportunities. According to the United Nations (UN), 6. 5 billion people will live in cities by 2050 , and more than $60 \%$ of the world's population will be concentrated in cities (Schuurman and Baccarne 2012). On the global scale, International Data Corporation (IDC) estimates that the steady increase in smart cities' expenses will rise to $\$ 158$ billion by 2022 (Twice as much as $\$ 80$ billion in 2018) (Visan and Ciurea 2020). Rapid population growth, besides putting considerable pressure on current cities, will pose serious threats to the future, leading to increased demand for services, housing facilities beyond the capacity of cities, as well as irreparable damage to the environment. As a result, cities face many challenges as their resources and infrastructure increase under increasing pressure (Breetzke 2016). Therefore, they always suffer from adverse consequences. Also, the sudden emergence of problems such as the recent Panorama of Covid-19 as well as advances in telecommunications, especially the Internet, along with the development of electronic devices, have changed people's everyday life and their minds in all aspects of economic and social fields (Das and Zhang 2020). The need of residents to a city that can meet all their requirements is considered the main need. The concept of "smart city" has been developed as a natural response to the phenomenon of urbanization, the economic importance of cities, and the increasing demand for more sustainable living (Nathali et al. 2018). The Corona pandemic also showed technological gaps and inequalities between different cities in different countries of the world. In addition to the health crisis, the economic and social crisis also emerged following the corona outbreak. That is why governments around the world should pay more attention to the sustainable communication and smartening of their cities. Cities must be able to link technology, leadership and management, and a strong culture of peaceful and interactive living. It is only in such circumstances that the worst destructive and negative effects of such crises can be overcome (Kunzmann 2020). According to the secretary of the IMD World Competitiveness Center, today, cities show different approaches to technology and corona pandemic management has become a major policy issue in cities (IMD 2019). The cities with higher technology in the world have managed to better cope with the corona and prevent its widespread spread.

In the study (Yang and Chong 2021) examines whether or not smart city projects play an important role in the prevention and control of COVID-19. based on COVID-19 validated data and investment of smart city projects in Chinese cities, the experimental results show that smart city projects have significantly reduced the number of COVID-19 approved cases. Also, the impact of smart city projects on COVID-19 in the intra-city development phase is stronger than the virus initiation phase, which are different for Cities with different population sizes. 
Today, the need to create a smart city and e-city as an irreplaceable solution to solve urban problems has been considered by city planners and city managers. A smart city is a model of conceptual urban development that means constructing a city based on information and communication technology (ICT). There are different definitions of the smart city depending on the level of economy and urban policy, but a simple definition is the use of ICT to improve competition and the quality of city life and pursue urban sustainability (Myeong 2018). In more general terms, the smart city is a city based on the technology platform for the "Internet of Things", whose daily processes are managed through the latest technologies in the world.

Many researchers, in order to clarify what makes a smart city, have divided this concept into several features and dimensions, and they say it is due to the complexity of the smart city as a comprehensive approach (Nathali et al. 2018). The 6-component model has been emphasized by many authors in this field. The European Union also ranks 70 cities accordingly (Giffinger 2007). Among the proposed designs and structures, most of the structures are an island and have not been seen integrative under a specific platform. The present paper designs this integrated Model as a graph for the first time and suggests that in this new proposed structure, the macro-social perspective is well seen and the presented meta-components are placed in this structure as an environment on the structure for the first time. Also, the shape of the final graph shows that the smart city is integrated and connected, and with this plan, it will get out of the island mode and will prevent overwork, data redundancy and waste of resources and energy, and will facilitate the work process. Also, due to its flexibility, the proposed structure enables different governments to extract and implement different subgraphs and requirements based on their social and cultural needs and other conditions of their society. In this article, first, the definitions and features of the smart city are reviewed, then the six-component structure approved by the majority of articles is examined and based on the function and position of each component, some appropriate sub-components are added to them, which ultimately leads to the formation of the proposed complete designed graph. Finally, due to their great importance, the proposed meta-components are added to the graph as an environment on the components and sub-components, and the final proposed design is presented.

\section{Review of literature}

Many researches have been done on smart city topics, most of which have been in the areas of smart city concepts, smart city architecture, and smart city features.

It is important to strike a balance between the goals of the subsystems and bring the whole system closer to the desired goals. Based on previous literature, in general, there are two main methods for modeling cities-analytical and heuristic ( Khana et al. 2021). In an analytical model involving the state of a system, examining all Input variables and measurement uncertainty for complex systems such as smart cities are very challenging (Rzevski 2016). Because these systems, in addition to being interconnected, operate autonomously and have a variety of components. For this reason, heuristic models (Stender and Kaiser 2017) are often used as an alternative when dealing with complex systems. heuristic algorithms or models find approximate solutions (near to the optimal) but within an acceptable time period of time (limited). They usually work based on estimates, intuition, experience or just common sense. Researchers in (Lom and Pribyl 2021) the field of modeling have classified smart city as a theory of systems cyberphysical systems (CPS). They used multi-agent systems (MAS) (Lom and Pribyl 2017) to model the smart city. In their research, they used a smart city agent as Building blocks for smart city modeling and the Smart City Evaluation Framework (SMACEF) to implement the practical example of smart city agents. The new approach in this paper is illustrated as cities of dynamic and nonlinear systems. Also in another study (Gillis et al. 2016), researchers developed an effective technique (IPA) (Importance-performance analysis) to discover the level of citizens' satisfaction with urban services, as well as prioritizing and improving future urban management services. They have been able to determine the level of satisfaction of the residents of Pans Kura, India with municipal services.

This study provides detailed and complete information about urban services that assist urban researchers, policymakers, urban and regional planners to develop urban planning and smart urban 
growth design. For this reason, models must be simulated dynamically with different scenarios and the results of these simulations can be considered as criteria. Therefore, in this article, we decided to introduce a more general and dynamic, integrated model of smart city so that simulations can be performed more accurately and comprehensively for a variety of purposes and applications.

In the following, first, the research done so far is reviewed and then, while expressing the existing shortcomings and deficiencies, the reasons and necessity of a new approach to the concept of smart city are examined and a new and integrated approach is presented.

\section{Definitions and features of smart city}

Over the past three decades, the concept of "smart city" has had different meanings for different people. Depending on the culture, social needs, general policies of the communities as well as the facilities available in a community, and depending on the stage of development of the city to change and reform, the definitions of smart city are constantly changing from one city to another and between communities. However, many researchers have tried to provide a unified definition of this concept, no comprehensive definition has been provided that is universally accepted. The concept of "smart city" was first introduced in 1990, when, given the novelty and importance of ICT in relation to modern infrastructure, the expression of perspectives on how technology affects cities came into focus (Yin et al. 2015). While in research (Giffinger and Haindl 2007), the smart city is considered as a city that is managed in a forward-looking way in the economy, people, governance, mobility, environment and it is built autonomously, independently and consciously based on the intelligent combination of citizen activities. In another view, (Janssen et al. 2017) the smart city is described as a smarter city: “A city that uses technology to transform its core systems and uses its vast resources to optimize the efficiency." According to the review of articles, it can be said that the concept of a smart city is about 30 years old and is evolving. In general, the smart city refers to the search for and identification of smart solutions that allow modern cities to improve the quality of services provided to citizens (Samih 2019).
Many researchers have also divided this concept into several features and dimensions in order to clarify what makes a smart city, and the reason for this is the complexity of the smart city as a comprehensive approach. This classification has undergone various changes during the years since the concept of smart city, for example, initially, the research (Neirott et al. 2014) consisted of four components: I also examined participation, education, technical infrastructure, and industry, as well as how these components relate to each other. Later, this concept was explained by six components: Smart people, smart living, smart environment, smart mobility, smart economy and smart governance (Giffinger 2007). To date, much research has been done on this popular classification. Another study examines a full understanding of the concept of a smart city by providing a classification in related areas of application, such as natural resources and energy, transportation and mobility, buildings, life, government, and the economy and people. It also shows that the evolution patterns of a smart city depend on the local context factors of that city (Neirott et al. 2014). From a slightly different perspective, the study (Alawadhi et al. 2017) identified the ten main components of public services in the smart city based on management and urban management: Policies and other institutional arrangements; Government; Public interaction and cooperation; Human capital and creativity; Knowledge economics and professional business environment; Built environment and urban infrastructure; natural environment and environmental sustainability; information and communication technology and other technologies; And data and information to analyze the concept of smart cities. In this paper, they agreed that the 10 components identified are for analytical purposes only, and some of them can be placed in more than one component and can also be categorized. Recently, experts have named eight components that affect different aspects of quality of life: interaction, community, security energy, water, waste, mobility, health care, economic development, and housing (Mohseni 2021). The quality of life of citizens has been emphasized as an added value in the definition of smart city, so it has been much discussed among experts.

Analysis of the studies shows that all the smart city models proposed in the literature acknowledge that smart cities are multidimensional systems, and even model that focus more on one particular dimension 
have not denied the importance of other dimensions. Many of the dimensions and elements suggested in the literature by different researchers often overlap. According to these researchers, the six dimensions in research (Giffinger and Haindl 2007) by considering the interactions between them (six components) are more comprehensive and in a way cover the dimensions of other researchers. For this reason, new research has used a six-component Model and tried to address various aspects according to the needs of research or geography, as well as the general policies of societies. In this regard, our proposed approach is based on a six-component structure (Giffinger and Haindl 2007) to expand the concept of smart city with a vision and approach integrating all needs and to provide a comprehensive map to facilitate understanding of needs and increase reliability and methodology selection that is proper for the implementation of this model. It should be noted that of course in different societies, according to social needs and current policies, the proposed model, which is drawn as a comprehensive graph, can be added by adding or subtracting different nodes or edges or highlighting the desired subgraph to achieve community need.

\section{Conventional smart city model}

The purpose of this article is to discuss the dimensions needed to build smart cities and provide smart services.

In particular, this study will focus on the infrastructure, governance and components of people's knowledge and how each of the different elements contributes. As a result, this research proves the importance of each dimension in building a smart city and providing smart services. Each component contains elements that allow smart cities to communicate, interact, and enable smart services. Figure 1 shows the 6-dimention structure of the smart city (Giffinger and Haindl 2007).

\section{Methodology}

As mentioned in the previous section, according to Fig. 1, a 6-dimension structure is currently used for the smart city, which alone is not enough and does not achieve the expansion and sustainability of the smart city in an integrated manner. In addition, the requirements are not precisely defined and increase the likelihood of errors occurring that extends to the entire life cycle of the system and reduce the fault tolerance and architectural reliability. Therefore, each of the 6 existing sections is divided into sub-dimension, each of which alone can include a sub-tree or sub-graph of executive projects and information technology applications. Due to the greater dynamics of the proposed design, a graph is finally drawn that shows the relationship, interaction and cooperation between different sections, including the main and sub-sections, even under different trees. Then, first, each section is analyzed and expanded independently, and finally, it is drawn in an integrated way. Eventually, three meta-dimensions are added to this detailed design and due to their high importance and the application of each of these meta-dimensions in each existing subtree, they are considered as meta-component to maximize stability, reliability and the ability to tolerate the proposed smart city model error and prevent duplication and to simplify the system requirements engineering (Zygiaris 2013) and ultimately strengthen the system life cycle by specifying the titles of the pilot projects.

\section{Smart people}

Before technology and infrastructure, smartening requires a creative, responsible, adaptable and productive citizen. In the absence of a smart and demanding citizen, none of the prepared smart services will be utilized. Therefore, the development of smart city strategies relies more on smart citizens than on technology. As mentioned in research (Giffinger 2007), a smart city cannot exist without smart people. Citizens are a key part of this knowledgebased urban development because people not only receive information, they are the driving force behind it (Hernan et al. 2018). Therefore, it is necessary to emphasize the need for better education, promotion of initiative and creativity of the people in order to increase the competencies of the citizens of smart cities (Mohanty 2017).

Based on our proposed model in Fig. 2, by smart people, we mean smart technical skills, use of smart education, human resources, capacity and productivity management, smart production of products and technology, smart data processing and analysis, which encourages creativity and improves and promotes 


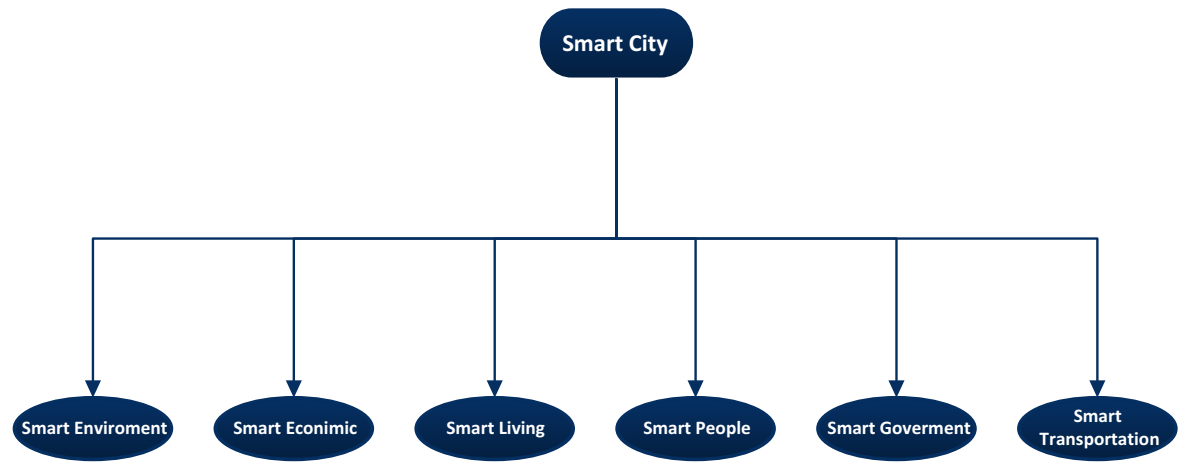

Fig. 1 The General six dimensions model of smart city

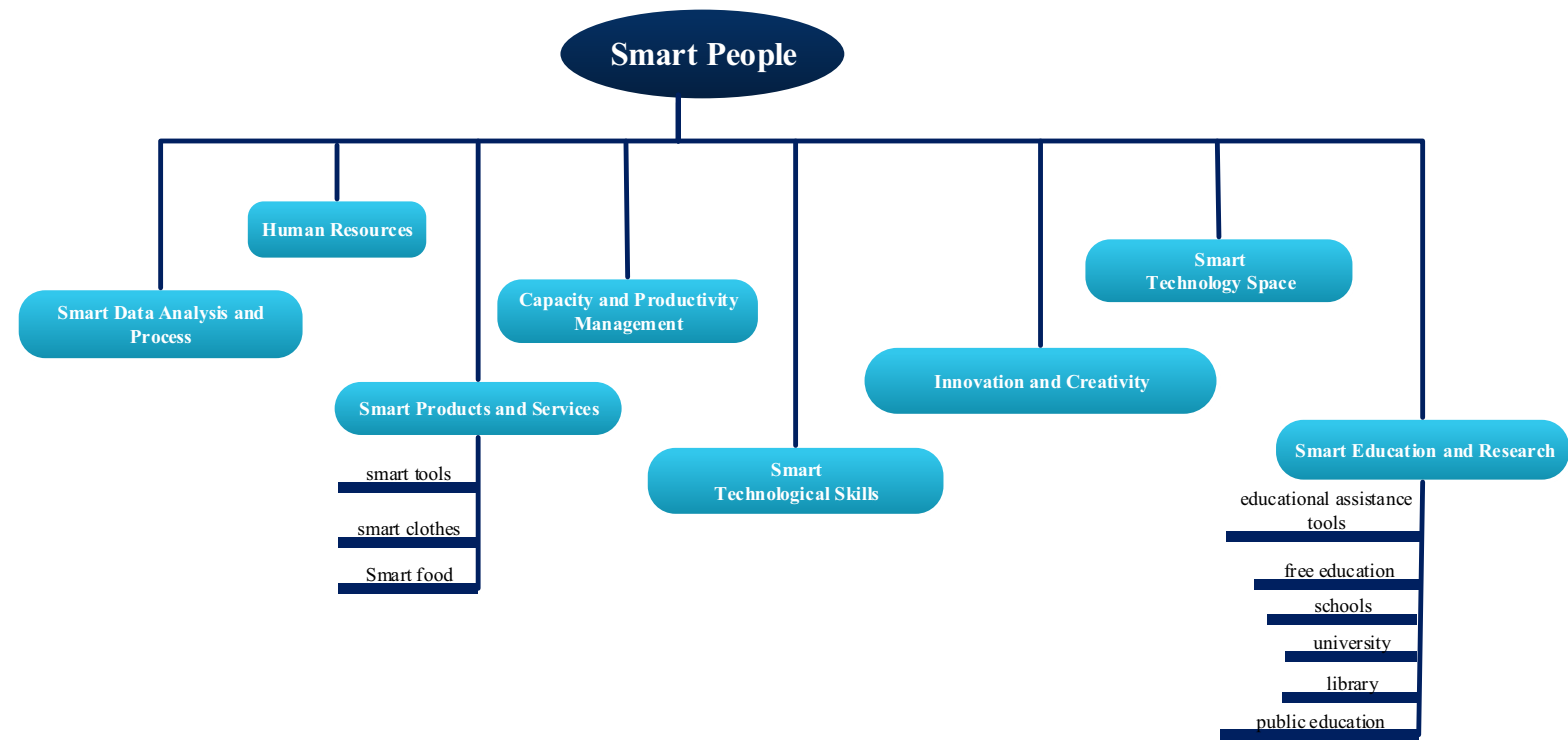

Fig. 2 Proposed sub model of smart people

innovation. In addition, the smart city allows members of the city to be active in participating in government and management of the city.

Smart people can be considered as one of the most important dimensions of a smart city, those who have technological skills, live in a technological environment, have access to virtual learning and learning space such as smart education, and their capabilities are managed with the aim of greater initiative and creativity (Loo and Tang 2019). In an environment where smart people are, the emphasis is on human resources, capacity management, data processing and analysis by the people themselves with the aim of making decisions and producing products and services. Human capital should be the main goal of a city and factors such as the level of education, culture and access to recreation are the criteria for measuring it. In general, a smart citizen produces and uses the human and social capital of the city. The smart production of goods such as clothing, food and tools can also help to improve the livelihood of the country and the country's economy (Nam and Pardo 2011).

Smart technologies are able to reduce many of the daily face-to-face interactions, thus helping to solve the problem of social distancing and prevent unnecessary gatherings and prevent further outbreaks when pervasive epidemics such as Quaid 19 are created. As can be seen, the corona virus has transformed the urban lifestyle in just a few months, putting technology at the forefront of countering the corona outbreak 
(Kylili et al. 2020). The role of online shopping and food delivery startups in meeting the essential needs of citizens has become more prominent than ever, and operators and IT companies have begun to track the prevalence and find more high-risk areas. This is not limited to today, and in an epidemic era, digital technologies should help track viruses to securely reopen urban infrastructures such as airports, public transportation, offices, and businesses to prevent or minimize outbreaks.

\section{Smart government}

Intra-city and sub-government governance, through which the services and interactions of private, public and civil organizations can be integrated in such a way that the city can function as an effective organism, is called smart governance (Loo and Tang 2019). According to our proposed method, several factors are involved in the formation of smart governance. Based on the Fig. 3 Important factors such as technology infrastructure, which itself includes centers, ICT satellite and network infrastructure, as well as the important discussion of participatory decisionmaking by smart technologies, have enabled citizens to participate, cooperate, and access their city management data and information. Smart governments need to have a smart feedback section that can track the consequences of smart decisions made in the smart city through public opinion polls. Other factors suggested for having smart governance include integration, which includes the integration of services and the integration of interactions, through which all government services, services and interactions are integrated into this section. Also, a smart government with the help of its smart management helps to strengthen the relations between the government and its stakeholders (citizens, businesses and other civil society organizations) inside the country and foreign policy management in relation to other governments and foreign countries, using the Innovative new method (Masik et al. 2021). This factor is based on the city's reputation in the world and maintaining its development process and international position, which is improved through strategic programs in the field of tourism and the attraction of foreign investment. All smart government and social services, including military and law enforcement forces, crisis headquarters, relief forces and government departments are provided under the supervision of the smart government. It can be said that smart governance specifically addresses the participation of citizens in smart municipalities (McCollough 2014; Nin et al. 2019). An e-municipality is an organization that uses information technology to provide its services in the field of municipal duties in an easy, fast, accessible, safe and

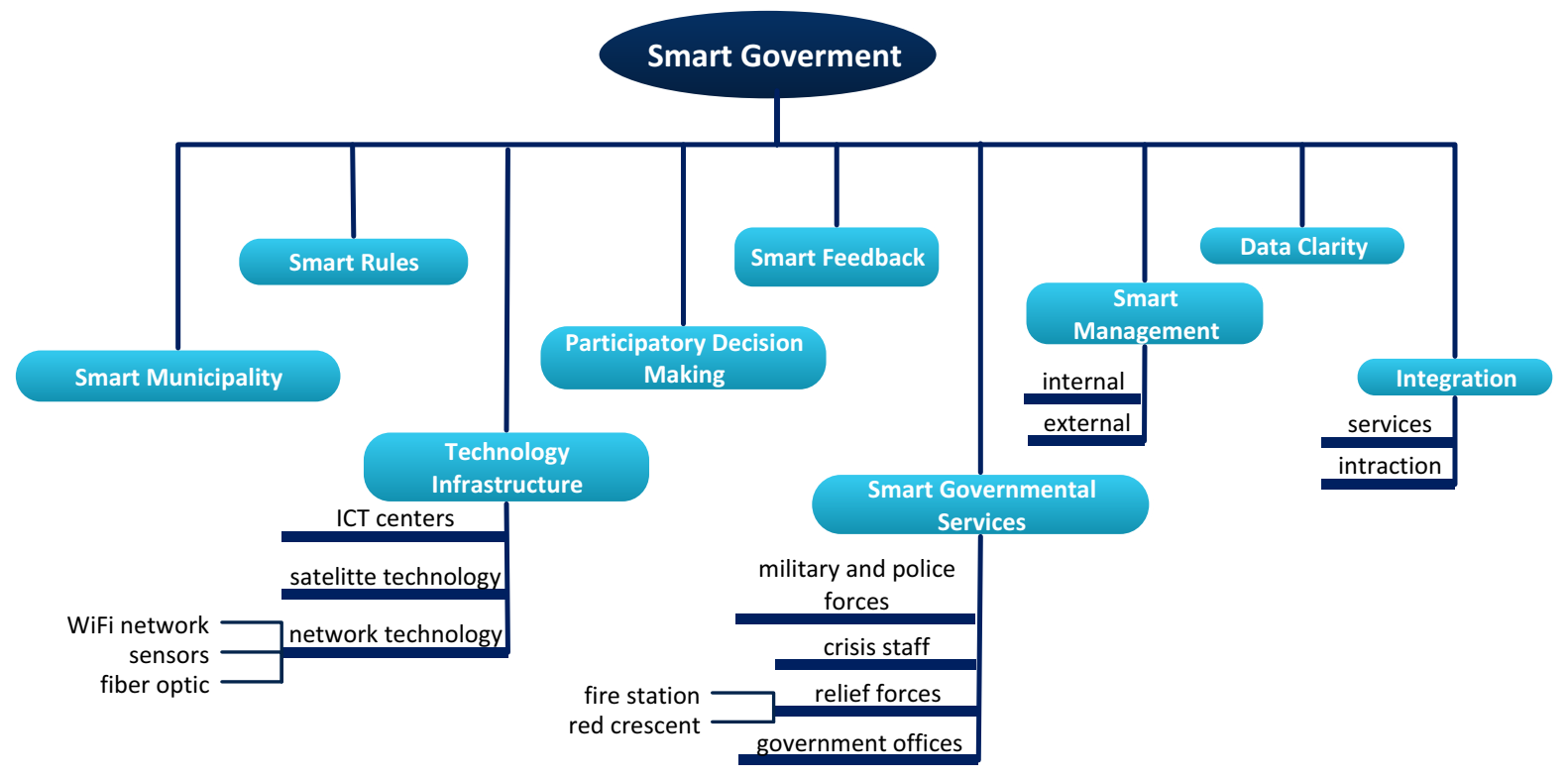

Fig. 3 Proposed sub model of smart government 
round-the-clock manner to the citizens. To create a smart municipality, awareness and efficient participation of citizens, as well as simultaneous investment in various urban infrastructure that can be implemented under the management of smart governance are needed. Due to the use of IoT technology to transmit and receive citizens' information for use in smart city applications, and also due to the confidentiality of information, the existence of rules and framework for the use of information is necessary and vital (João and Serralvo 2019). Problems such as the COVID-19 epidemic have changed public opinion and increased public confidence in data sharing with the government and encouraged governments to address these real and potential harms. The most important government response in this time should be a data privacy policy that can reassure citizens that their data are collected for legitimate purposes (Sharifi and Khavarian-garmsir2021). According to Fig. 3, in our proposed model, determining smart rules is one of the essential tasks of smart governance.

\section{Smart environment}

One of the most important components of the smart city that has recently attracted the attention of many researchers is the smart environment. The smart environment seeks to improve the quality of life of citizens by creating healthy and safe living conditions (General et al. 2002). Based on our proposed model, according to Fig. 4, the smart environment includes important factors such as smart energy, smart energy distribution network, smart pollution monitoring and control, smart buildings, increasing the quality of natural resources, smart health and smart advertising.

According to Fig. 4, each of these key factors includes a subset to achieve their goal. In order to optimize energy consumption, the main purpose of which is to promote more use of renewable resources and less consumption of natural resources (Programme 2012), smart environment provide the possibility of intelligent measurement and monitoring, as well as better monitoring and control of pollution in the city through technological solutions. smart monitoring of pollution control can include monitoring noise and climate pollution (Roy et al. 2018), waste management (Alqahtani et al. 2020; Idwan et al. 2020), creating a sustainable green city with the aim of reducing carbon (Innovation and Carbon 2016), and controlling urban drinking water. In addition to managing the use of more renewable resources such as clean and nuclear energy, smart energy also monitors how smart water, electricity and gas networks are serviced, as well as how to optimize energy consumption (Villa-arrieta and Sumper 2019). With the increase of the urban population and the great need of citizens to discuss health, it is necessary to provide smarter services in the field of health. Smarter ways to provide treatment services can reduce costs and establish more effective communication between healthcare professionals to provide access to patients' essential information. When nurses and physicians have access to patient information, they can work together in new ways to best care for patients (Rath and Pattanayak 2019). A smart environment can achieve great progress in smart health by using the facilities of the Internet of Things. With the help of monitoring devices such as attachment sensors, wearables and biosensor sensors in the body, the Internet of Things continuously monitors the vital signs of patients remotely, and by using connected devices, physicians can continuously monitor the condition of patients so they can provide emergency and timely services in case of critical situations (Moore and Van Pham 2019). Citizens of the smart city can also use the services of smart offices and hospitals without the need for a face-to-face visit. In addition to saving citizens time and money, this greatly contributes to the quality of timely and emergency services.

\section{Smart economic}

Smart economy refers to the competitiveness of a city based on its innovative approach in new business models, e-commerce, creating innovative and creative products, entrepreneurship, innovative services based on ICT, smart sales, smart industry, smart agriculture and smart tourism. The concept of a smart economy provides effective measures to strengthen the city's economy, by improving the business environment and improving its attractiveness for investors and talents to use the information and communication technologies (ICT) to grow the economy in an innovative way( Nin et al. 2019; Kumar and Dahiya 2017).

According to Fig. 5, our proposed model includes all smart activities based on economic factors, profitable activities, sustainability and economic growth, and all smart economic activities fall into this 


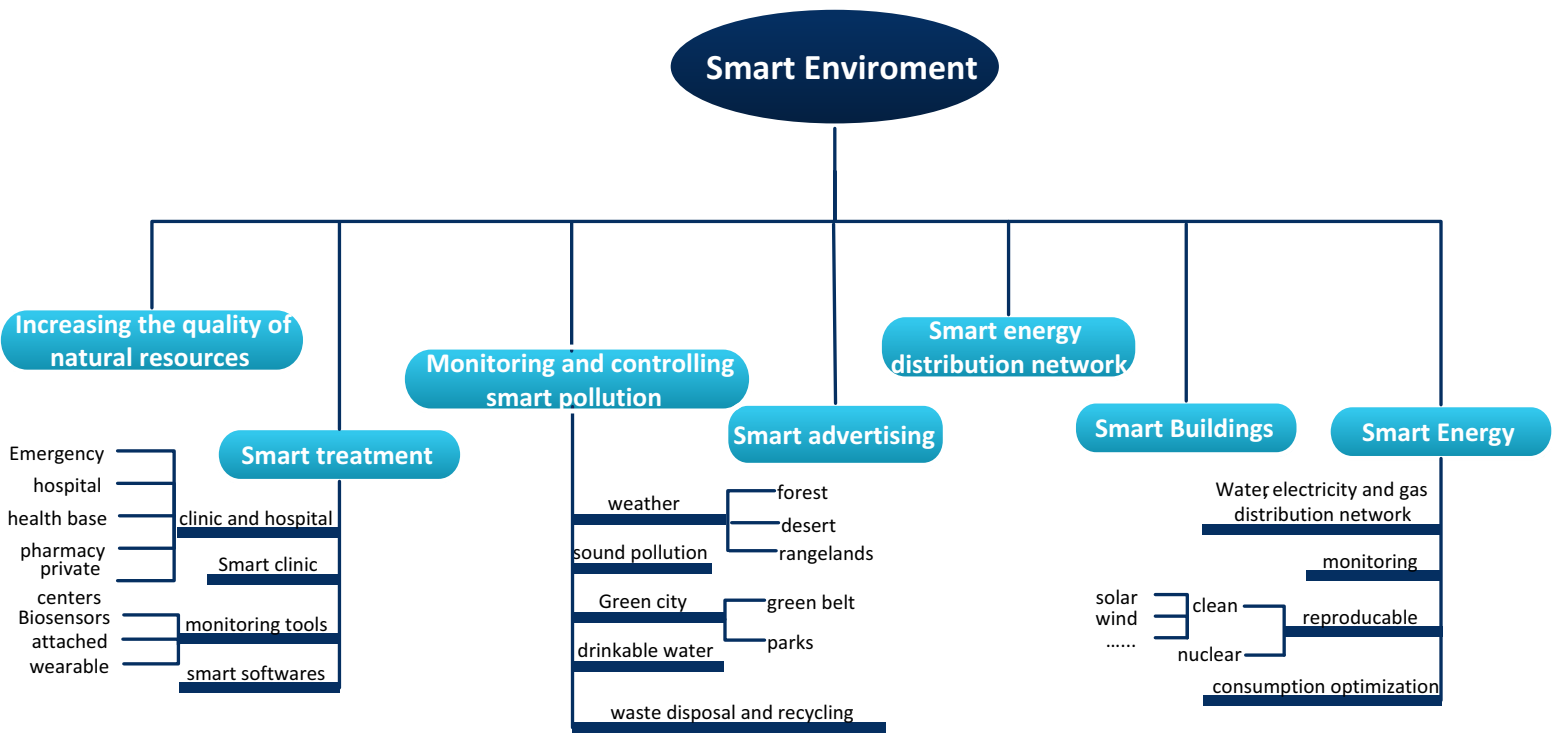

Fig. 4 Proposed sub model of smart environment

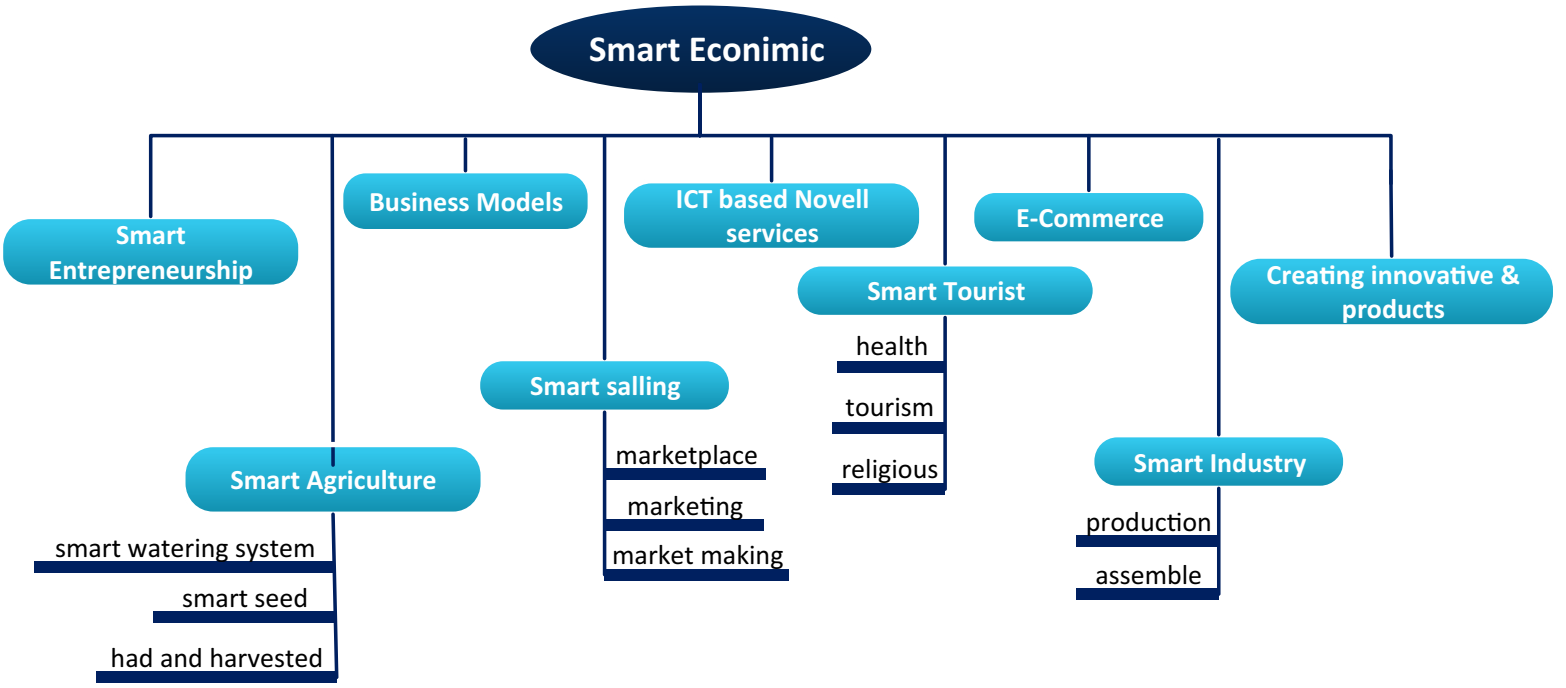

Fig. 5 Proposed sub model of smart economic

subgroup. For example, smart sales are one of the most important and necessary factors to achieve a smart economy, which includes supply chain, smart marketing, marketing research, and market-making. Also, smart agriculture has been able to use the Internet of Things to reduce energy consumption as well as the costs associated with the use of manpower by using smart seeds, smart irrigation, and smart harvesting.

is an industry that today accounts for a large share of the world's economic activity and is estimated to account for over a third of the world's total trade in services (Al-omari and Alqaralleh 2020). Smart cities can strengthen the country's economy by creating smart tourism. Smart tourism means using smartphone-based applications to provide tourism services with the aim of providing easy access to tourist and religious sights smartly, as well as smart health facilities for its tourists (Nitti et al. 2017). In general, a smart economy is an economy in which available resources are used to develop and implement 
innovative solutions for sustainable economic growth and a steady increase in gross national and domestic income, and an increase in the trade balance (Zygiaris 2013).

The outbreak of the Corona virus has also provided an opportunity to boost the smart economy and move traditional businesses to online businesses, despite heavy losses and the closure of many businesses.

In the first 6 months of the corona virus outbreak, business surveys show more than one billion online purchases in more than 34 countries (Bhagavan et al. 2018). Naturally, other activities in the smart city and even the virus epidemic have economic effects, so there is certainly a connection between this subgroup and other subgroups and they form a graph.

\section{Smart living}

The topic of smart living seeks to improve the quality of life of citizens by providing safe and healthy living conditions (General et al. 2002). One of the benefits of living in smart cities is the easy use of various cultural and social services. Based on the proposed model presented in Fig. 6, these services include the use of cultural centers, libraries, religious sites, ancient sites and recreational sites in a smart manner.

Figure 6 shows smart living by living with a technological style, behaviors and uses based on the technological space, a healthy, safe and refreshing lifestyle, the existence of diverse cultural facilities in the city, quality accommodation with smart solidarity. Many cities focus mainly on the advancement of technology, but the social solidarity that is essential for the comprehensive development of a city is often overlooked. This factor is defined based on the level of coexistence between different classes of people in a city who have different incomes, cultures, ages, and occupations (General et al. 2002). As an example of indicators for smart living, we can mention the position of technology in various aspects of life. The relationship between this subgroup and other subgroups is inevitable because smart living requires a healthy environment, personal and social security, adequate income, and individual and public health. Therefore, the final relationship between this subgroup in the form of a graph with other subgroups is obvious and established.

\section{Smart transportation}

Intelligent Mobility, by establishing an integrated ICT infrastructure to provide transportation and logistics services to institutions and people, considers a safe, clean, stable, integrated and diversified transportation system, reducing transportation costs and time, and reducing air pollution. According to our proposed model in Fig. 7, smart transportation means support for integrated ICT infrastructure, integrated transportation, logistics systems, clean transportation, safe transportation, smart urban and road transportation. Given that the most important goal of smart transportation is to reduce air pollution and carbon footprint, clean transportation systems can include drones, hybrid vehicles, electric vehicles and bicycles that have the lowest levels of pollution. Smart transportation also solves.

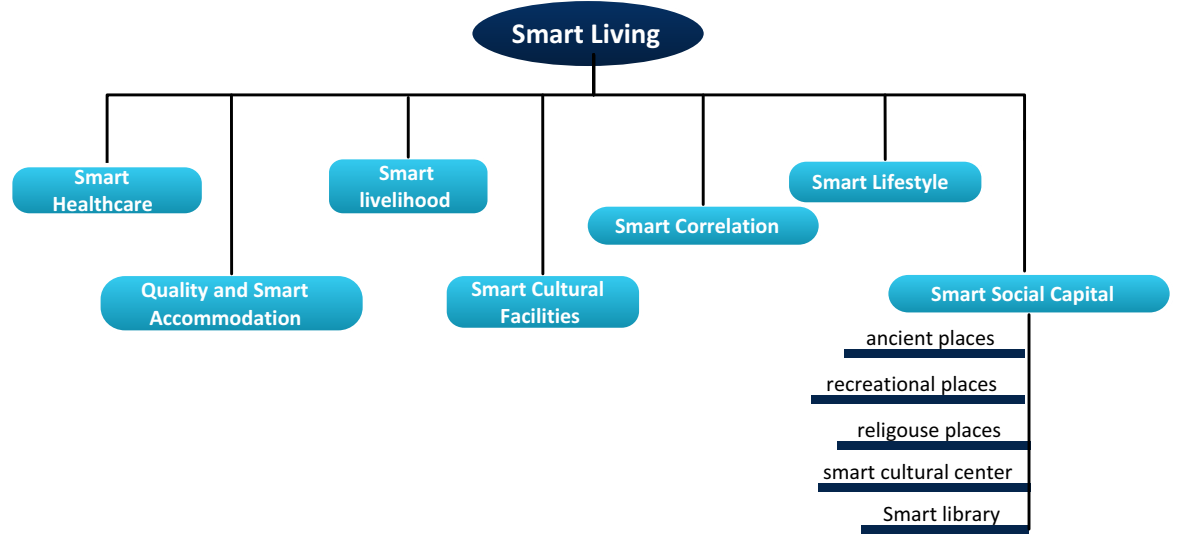

Fig. 6 Proposed sub model of smart living 


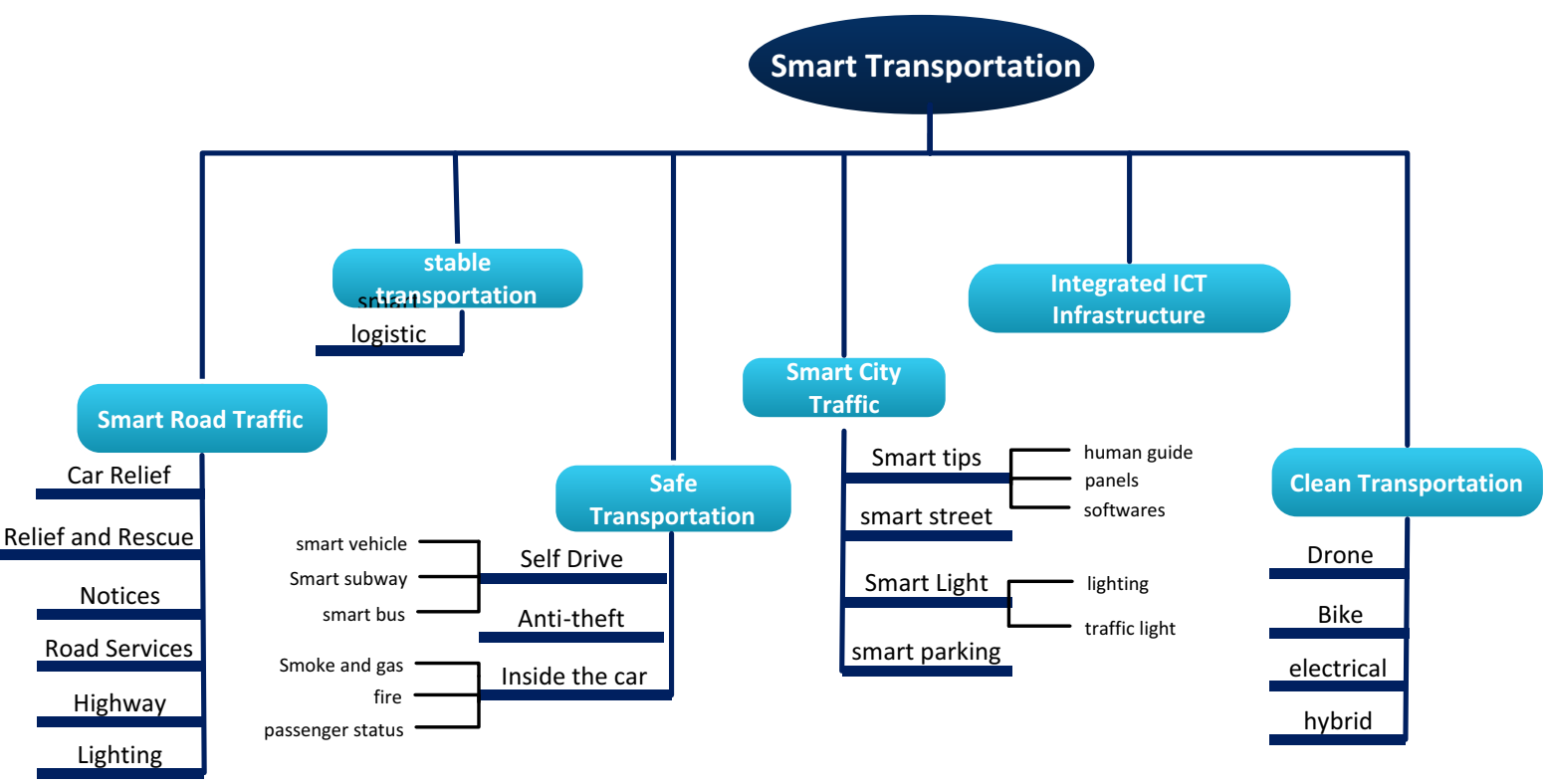

Fig. 7 Proposed sub model of smart transportation

the problem of road traffic with the help of smart rescue services, smart highways, smart car assistance, smart road lighting, smart notices and other road services. With the increase of urban life and the number of vehicles in cities, smart transportation with the approach of smart reduction of urban traffic uses the smart traffic guidance system, which includes software, signs and human guidance to know the traffic situation on the streets (Soomro et al. 2018), it has also created smart streets (Ahmed and Rani 2017) and smart parking lots (Ma and Xue 2020), in the city. In addition, to reduce energy consumption, it has used a smart lighting system (Bhagavan et al. 2018; Jia et al. 2018) for traffic lights and urban lighting in the city. Transportation safety and security is one of the most important issues for the urban and road transport industry.

Road and urban accidents incur high medical and disability costs for governments and insurance companies. According to the proposed model in Fig. 7, smart transportation can provide safety and security of urban and road transport through smart controlling of the safety inside the vehicle, factors such as fire, smoke and gas, the condition of passengers and driver, as well as the safety of vehicles such as buses, subways and cars and the use of smart anti-theft system. Another factor influencing smart transportation is the creation of sustainable smart transportation by smart logistics. By smart logistics, the Internet of Things has been able to reduce manual operations and replace automated options in the freight transport process. Smart logistics also allows the provision of load information (work) at the moment (Korczak and Kijewska 2019.

\section{Integrated smart city model}

considering the mentioned cases and the extensions presented in different sections before, a general diagram for the integration of smart city model according to Fig. 8 can be proposed.

As can be seen in Fig. 8, the proposed diagram is first plotted as a graph that connects the different parts and identifies the existing relationships.

It is obvious that different societies slightly change or localize the connections of this graph based on their cultural, economic and political needs. In all the cases specified in this graph, there are common concepts. In order to integrate and prevent island implementation, these concepts were first extracted from the graph in three meta-components and drawn as an environment on all parts. Thus, while creating higher security and integration, it prevents overwork, the possibility of 


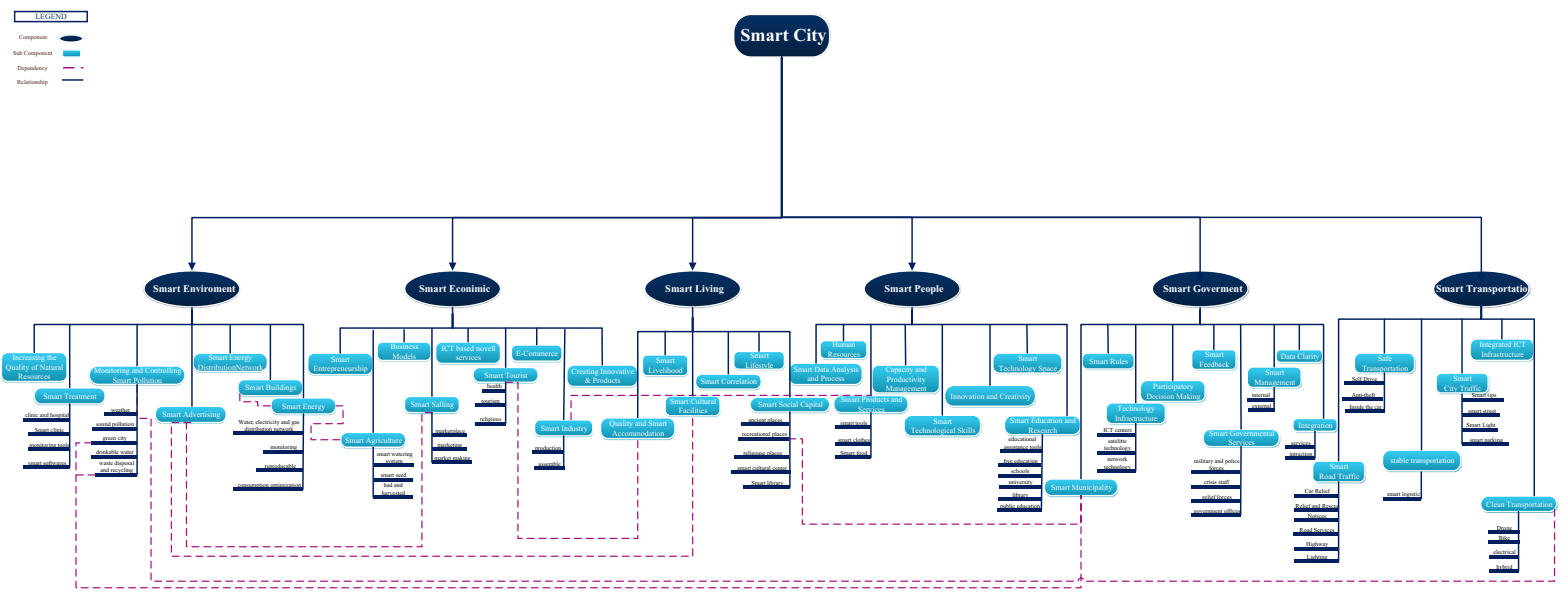

Fig. 8 Proposed graph type model of smart cities

data redundancy and related errors, and leads to increased reliability and error tolerance.

According to Fig. 9, these three main metacomponents are security, knowledge, and infrastructure management. Security includes the three sub meta-components of physical security, information security and Information assurance, and all security issues related to the smart city are included in a general and comprehensive way. In order to create public trust and integrated security for all information, including individual, group and even classified information, as well as information extracted from the Internet of
Things, all security matters must be widely distributed throughout the smart city and adhere to integrated security protocols.

One of the most important issues in societies and all its levels is the optimal use of information, experiences and strengths and weaknesses of previous practices. In other words, the knowledge created in a society, whether explicit or implicit, must be shared and managed by users. Also, this knowledge should be expanded and re-shared for optimal use.

For this purpose, the sub Meta-components of knowledge management and knowledge engineering

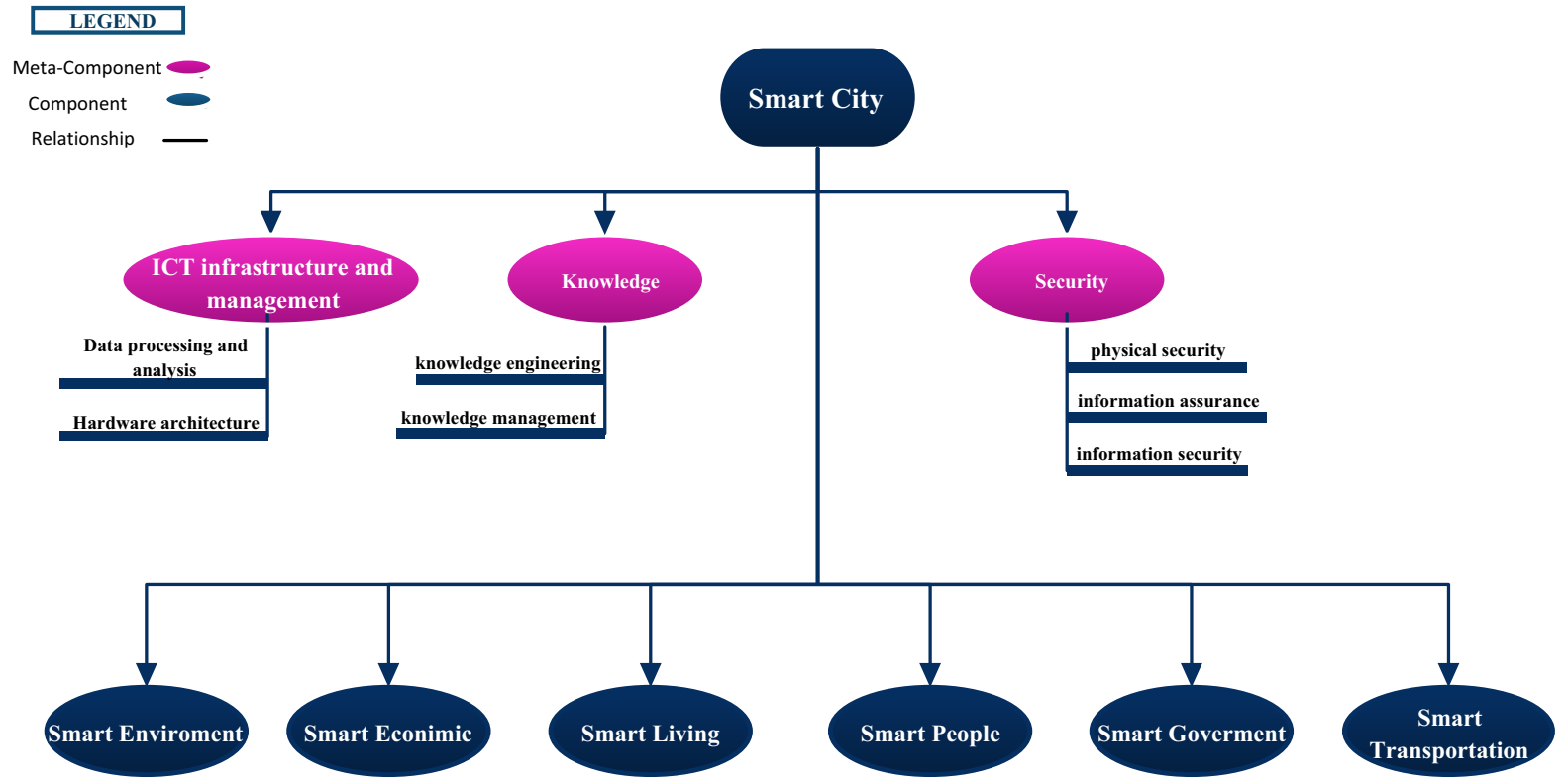

Fig. 9 Meta components of smart city 
on the whole smart city are included in this chart. It is natural that the vast majority of all smart city operations are based on ICT-dependent technology, and the flow of data, including individual, group, IoTbased data, requires proper hardware infrastructure and proper software processing. To this end, the global ICT and management infrastructure component, including two sub meta-components of data processing and analysis and hardware architecture, has been added to this structure. Figure 10 shows an extended example of our proposed model.

Based on Fig. 10, the proposed model contains comprehensive monitoring meta-components and subcomponents of the smart city graph. Breaking each sub-component into newer sub-components determines the titles of the executive projects. Thus, the position and relationship of each executive project with other departments is more precisely known to analysts, designers and implementers of executive systems and prevent rework, redundancy, side effects and island systems, and by specifying the levels of work following the identification of system requirements, requirements engineering (Nitti et al. 2017), and selecting appropriate methodologies for implementing executive projects will be easier. In this way, in addition to the above, the reliability and error tolerance of the smart city can be significantly increased.

\section{Conclusion}

In previous research based on the current situation and thematic literature, the concept of smart city was mostly proposed and implemented as an island with six main components in different societies. Also due to the increase in urbanization and the connection of smart cities with the challenges that arise in implementing and integrating the urban model, a suitable solution for the concept of integrated smart city Was not provided to your best knowledge and some essential concepts such as security, ICT infrastructure and knowledge are not seen integrative in these structures. In order to integrate, prevent data redundancy, ease of access, create security at different levels, the present study Provides a flexible, integrated, localizable dynamic model with a new approach that breaks down six core components into several sub components that creates a graph-like model, in which each sub component represents a set of implementable smart projects in different communities.

It is expected that by using this proposed model in various smart city applications, the island like projects have an integrated form and given the meta-components that has been proposed in the structure of the smart city for the first time It avoids overwork, data redundancy and the potential risks of previous methods, and builds public trust in governments and smart communities to share data. It can also be expected if this model is established in communities In addition to

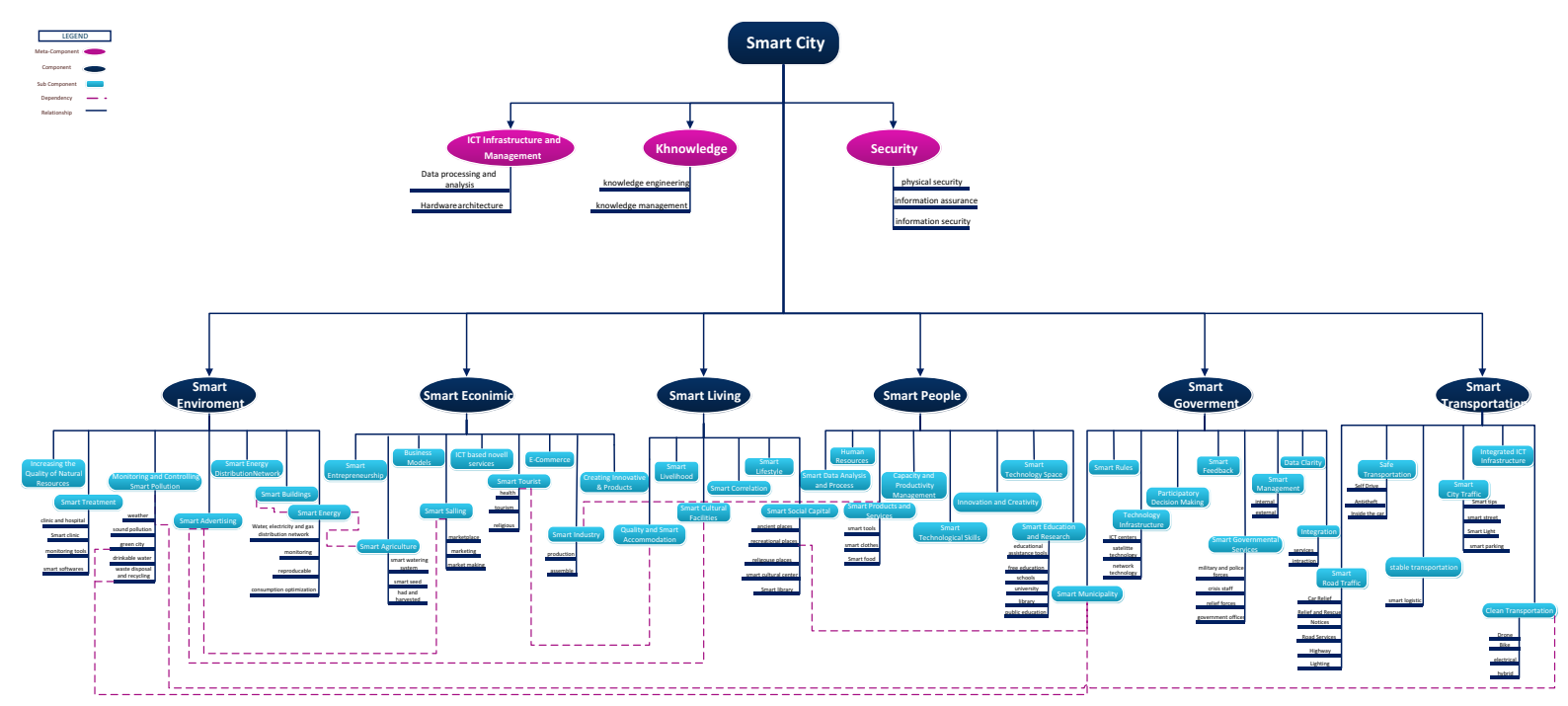

Fig. 10 Integrated Model of components, meta-components and sub meta-component for integrated smart cities 
a prosperous life, a sustainable economy, a healthier environment and easier management of communities, we will be able to intelligently predict sudden events such as natural disasters or recent problems in communities such as outbreaks of dangerous diseases like COVID-19 and the like with more ease and at the lowest cost and least disruption to people's daily lives and also to counteract the reduction of economic and scientific decline and health.

For future work, to expand the proposed model, it is suggested that the titles of applicable projects with the ability to implement in Smart cities will be listed and added to the proposed model. Also new protocols to increase public security and Internet of things-based data will be inevitable in order to complete the proposed model. Localization in different communities with Attention to restrictions, culture, general policies and economics and other factors should be applied on the proposed model by members of each community separately. The proposed model also has the capability of modeling by the use of effective IPA technique or exploratory modeling methods such as multi-agent systems (MAS).

Acknowledgements The authors are thankful to anonymous reviewers for their valuable comments and suggestions that helped improving the quality of the paper.

Authors' contributions Not applicable.

Funding Not applicable.

Availability of data and materials Not applicable.

\section{Declarations}

Conflict of interest The authors have no conflict of interest.

\section{Appendix}

And better understanding Therefore, it is recommended that more research be done on the factors influencing the creation of a sustainable and integrated smart city.

\section{References}

Ahmed, S. H., \& Rani, S. (2018). A hybrid approach, Smart Street use case and future aspects for internet of things in smart cities. Future Generation Computer Systems, 79(3), 777-974.

Alawadhi, S. et al. (2017). Building understanding of smart city initiatives to cite this version: HAL Id: hal-01543596. Building Understanding of Smart City Initiatives.

Alqahtani, F., Al-Makhadmeh, Z., Tolba, A., \& Said, W. (2020). Internet of things-based urban waste management system for smart cities using a Cuckoo Search Algorithm. Cluster Computers, 23, 1769-1780. https://doi.org/10.1007/ s10586-020-03126-x.

Al-omari, A. H., \& Alqaralleh, B. A. Y. (2020). International journal of advanced and applied sciences smart tourism and location-based services architectural model. 7(4), 113-120.

Bhagavan, K., Sai Saketh, S., Mounika, G., Vishal, M., \& Hemanth, M. (2018). IOT based intelligent street lighting system for smart city. International Journal of Engineering Technology, 7(32), 345-347.

Breetzke, T., (2016) T u ivr s c c d c, pp. 1-14.

Das, D., \& Zhang, J. J. (2020). Pandemic in a smart city: Singapore's COVID-19 management through technology and society. Urban Geography, 42(3), 408-416. https://doi. org/10.1080/02723638.2020.1807168

General, D., Internal, F. O. R. \& Policy, S. (2002). No Title.

Giffinger, R., Fertner, C., \& Meijers, E. (2007). City-ranking of European medium-sized cities city-ranking of European medium-sized cities. January, 2007.

Giffinger, R., \& Haindl, G. (2007). Smart cities ranking: an effective instrument for the positioning of cities? pp. 703-714, [Online]. Available: https://upcommons.upc. edu/bitstream/handle/2099/11933/05_PROCEEDINGS_ M5_01_0014.pdf.

Gillis, R., et al. (2016) Metadata of the article that will be visualized in OnlineFirst. European Biophysics Journal.

Idwan, S., Mahmood, I., Zubairi, J. A., \& Matar, I. (2020). Optimal management of solid waste in smart cities using internet of things. Wireless Personal Communications, 110(1), 485-501. https://doi.org/10.1007/s11277-01906738-8

IMD, (2019). IMD world digital competitiveness ranking 2019. IMD World Competitiveness Center, p. 180. [Online]. Available: https://www.imd.org/globalassets/wcc/docs/ release-2017/world_digital_competitiveness_yearbook_ 2017.pdf.

Innovation, H., \& Carbon, L. (2016). Today's cities into livable. Hernan, L., Pinochet, C., Romani, G. F., De Souza, C. A., De Souza, C. A., \& Rodríguez-abitia, G. (2018). Intention to live in a smart city based on its characteristics in the perception by the young public. https://doi.org/10.1108/ REGE-06-2018-0077.

Janssen, M., Glassey, O., \& Scholl, H. J. (2017). Preface. In: Lectures Notes in Computer Sciences (including Subseries Lecture Notes in Artificial Intelligent Lecture Notes in Bioinformatics), vol. 10428 LNCS, pp. V-VI. https://doi. org/10.1007/978-3-319-64677-0. 
Jia, G., Han, G., Li, A., \& Du, J. (2018). SSL: Smart street lamp based on fog computing for smarter cities. IEEE Transactions on Industrial Informatics, 14(11), 4995-5004. https://doi.org/10.1109/TII.2018.2857918

João, N., \& Serralvo, F. A. (2019). A systematic review of smart cities and the internet of things as a research topic, pp. 1115-1130.

Khana, A. Aurangzebb, K., Alhusseinc, M., \& Aslam, S. (2021). Multiscale modeling in smart cities: A survey on applications, current trends, and challenges. June, 2021. https:// doi.org/10.20944/preprints202106.0008.v1.

Korczak, J., \& Kijewska, K. (2019). ScienceDirect smart logistics in the development of smart cities smart logistics in the development of smart cities green cities 2018 . Transportation Research Procedia, 39(2018), 201-211. https://doi.org/10.1016/j.trpro.2019.06.022

Kumar, T. M. V., \& Dahiya, B. Smart Economy in Smart Cities.

Kunzmann, K. R. (2020). Smart cities after covid-19: Ten narratives. Display, 56(2), 20-31. https://doi.org/10.1080/ 02513625.2020.1794120

Kylili, A., Afxentiou, N., Georgiou, L., \& Panteli, C. (2020). The role of Remote Working in smart cities: Lessons learnt from COVID-19 pandemic. Energy Sources, Part a: Recovery, Utilization, and Environmental Effects. https:// doi.org/10.1080/15567036.2020.1831108

Lom, M., \& Pribyl, O. (2021). Smart city model based on systems theory. International. Journal of Information. Management, 56, 102092. https://doi.org/10.1016/j.ijinfomgt. 2020.102092.

Lom, M., \& Pribyl, O. (2017). Modeling of smart city building blocks using multi-agent systems. Neural Network World, 27(4), 317-331. https://doi.org/10.14311/NNW.2017.27. 018

Loo, B. P. Y., \& Tang, W. S. M. (2019). 'Mapping' smart cities 'mapping' smart cities. Journal of Urban Technology, 26(2), 129-146. https://doi.org/10.1080/10630732.2019. 1576467

Ma, X., \& Xue, H. (2020). Intelligent smart city parking facility layout optimization based on intelligent IoT analysis. Computer Communication, 172(15 April 2021), 10-18. https://doi.org/10.1016/j.comcom.2020.01.055

Masik, G., Sagań, I., \& Scott, J. W. (2021). Smart City strategies and new urban development policies in the Polish context. Cities, 108, 102970. https://doi.org/10.1016/j.cities.2020. 102970.

McCollough, M. (2014). The digital city. Rethinking the American City: An International Dialogue, pp. 167-191.

Mohseni, H. (2020). Public engagement and smart city definitions: A classifying model for the evaluation of citizen power in 2025 Tehran. GeoJournal, 86, 1261-1274. https://doi.org/10.1007/s10708-019-10126-x.

Mohanty, S. P. (2017). Everything you wanted to know about smart cities everything you wanted to know about smart cities. October, 2017. https://doi.org/10.1109/MCE.2016. 2556879.

Moore, P., \& Van Pham, H. (2019). A fog computing model for pervasive connected healthcare in smart environments. International Journal of Grid and Utility Computing, 10(4), 375-391. https://doi.org/10.1504/IJGUC.2019. 100899
Myeong, S. (2018). A study on determinant factors in smart city development: An analytic hierarchy process analysis. https://doi.org/10.3390/su10082606.

Nam, T., \& Pardo, T. A. (2011). Conceptualizing Smart city with dimensions of technology, people, and institutions. pp. 282-291.

Nathali, B., Khan, M., \& Han, K. (2018). Towards sustainable smart cities: A review of trends, architectures, components, and open challenges in smart cities. Sustainable Cities and Society, 38, 697-713. https://doi.org/10.1016/j.scs.2018. 01.053

Neirotti, P., De Marco, A., Cagliano, A. C., Mangano, G., \& Scorrano, F. (2014). Current trends in smart city initiatives: Some stylised facts. Cities, 38(June), 25-36. https://doi. org/10.1016/j.cities.2013.12.010

Nin, I., Maja, Ć., \& Jadri, M. (2020). International Journal of Information Management Smart city research advances in Southeast Europe. International Journal of Information Management, 58(June 2021), 102127. https://doi.org/10. 1016/j.ijinfomgt.2020.102127.

Nitti, M., Pilloni, V., Giusto, D., \& Popescu, V. (2017). IoT Architecture for a sustainable tourism application in a smart city environment. Mobile Informations System. https://doi.org/10.1155/2017/9201640.

Programme, N. E. (2012). UNEP promotes environ- mentally sound practices globally and in its own activities. This publication is printed on $100 \%$ eco-fibers paper, using vegetable-Based inks and other eco-friendly practices. Our distribution policy aims to reduce UNEP's car.

Rath, M., \& Pattanayak, B. (2019). Technological improvement in modern health care applications using internet of things (IoT) and proposal of novel health care approach. International Journal of Human Rights in Healthcare, 12(2), 148-162. https://doi.org/10.1108/IJHRH-01-2018-0007

Roy, K. S., Sowmya, S., Manasa, M., Alekhya, D., \& Abhinav, P. (2018). Decentralized weather monitoring system for smart cities, 7(2), 67-69.

Rzevski, G. (2016). Managing complexity: Theory and practice. In: 2016 11th System of Systems Engineering Conference (SoSE). September, 2016. https://doi.org/10.1109/ SYSOSE.2016.7542915.

Samih, H. (2019). Smart cities and internet of things. Journal of Information Technology Case and Application, 21(1), 3-12. https://doi.org/10.1080/15228053.2019.1587572

Schuurman, D., Baccarne, B., De Marez, L., \& Mechant, P. (2012). Smart ideas for smart cities: Investigating crowdsourcing for generating and selecting ideas for ICT innovation in a city context. Journal of Theoretical and Applied Electronic Commerce, 7(3), 49-62. https://doi.org/10. 4067/S0718-18762012000300006

Sharifi A., \& Khavarian-garmsir, A. R. (2021). Contributions of smart city solutions and technologies to resilience against the COVID-19 pandemic: A literature review.

Soomro, S., Miraz, M. H., Prasanth, A., \& Abdullah, M. (2018). Artificial intelligence enabled IoT: Traffic congestion reduction in smart cities. In: IET Confernce on Publications, vol. 2018, no. CP747. https://doi.org/10.1049/cp. 2018.1381.

Stender, P., \& Kaiser, G. (2017). The use of heuristic strategies in modelling activities to cite this version: HAL Id: hal01933448. In: Proceedings of the. Tenth Congress 
European Society for Research in Mathematics Education, pp. 1012-1019.

Villa-arrieta, M., \& Sumper, A. (2019). Applied sciences contribution of smart cities to the energy sustainability of the binomial between city and country 9(16), 32-47.

Visan, M., \& Ciurea, C. (2020). CCC publications smart city: Concepts and two relevant components, vol. 2022.

Yang, S. S., \& Chong, Z. (2021). Smart city projects against COVID-19: Quantitative evidence from China. Sustainable Cities and Society, 70(February), 102897. https://doi. org/10.1016/j.scs.2021.102897.
Yin, C. T., Xiong, Z., Chen, H., Wang, J. Y., Cooper, D., \& David, B. (2015). A literature survey on smart cities. Science China Information Sciences, 58(10), 1-18. https://doi. org/10.1007/s11432-015-5397-4

Zygiaris, S. (2013). Smart city reference model: Assisting planners to conceptualize the building of smart city innovation ecosystems, 4, 217-231. https://doi.org/10.1007/ s13132-012-0089-4. 